\title{
RELOCALIZACIÓN DE LOS SISTEMAS DE PRODUCCIÓN AGRO-ALIMENTARIA EN LA UNIÓN EUROPEA
}

\author{
Brian Ilbery \\ Departamento de Geografía, Universidad de Coventry, Priory Street, \\ Coventry, Reino Unido, CV1 5FB (e-mail: b.ilbery@coventry.ac.uk)
}

\begin{abstract}
Resumen: A pesar de las tendencias mundializadoras vigentes en los sistemas agroalimentarios, hay todo un movimiento hacia lo que se ha dado en llamar relocalización de la producción y el consumo alimentarios. Tal movimiento se relaciona con un conjunto de factores y en este artículo se examinan los intentos para estimular tal realocalización de la producción alimentaria a escala internacional (Unión Europea) y nacional (Reino Unido). Los estudios de varios casos de "denominaciones de origen protegida", de "indicaciones geográficas protegidas", asi como de agrupaciones productivas regionales de diversa índole, ponen en evidencia que los esfuerzos para "vincular los productos a los lugares", han tenido hasta la fecha un impacto relativamente escaso, especialmente en aquellas regiones marginadas por los procesos de reestructuración agraria. En todo caso se necesita investigar más sobre tales procesos, y especialmente en relación con conceptos como arraigo social, calidad y certificación, así como desarrollo rural endógeno.
\end{abstract}

Palabras clave: Geografía agraria, mundialización, denominaciones de origen, Unión Europea.

\begin{abstract}
Despite globalising tendencies in food supply systems, there is a movement towards the relocalisation of food production and consumption. Such a movement relates to a range of factors and this paper examines attempts to encourage the relocalisation of food supply systems at international (EU) and national (UK) scales. Case studies of PDOs/PGIs and regional food groups show that efforts to link 'product to place' have, so far, had relatively little impact on local economic development, especially in those rural areas marginalised by agricultural restructuring processes. More research is needed on the relocalisation of food supply systems, in relation to such concepts as social embeddedness, quality and certification, and endogenous rural development.
\end{abstract}

Key words: Agrarian Geography, Relocalisation, Protected Designation of Origin /Protected Geographical Indication, European Union, United Kingdom. 


\section{Sistemas de producción agro-alimentaria globales y locales ${ }^{1}$}

Las regiones europeas se caracterizan por distintas combinaciones de sistemas de producción agro-alimentaria regionales y locales. Pero no cabe duda de que desde los años setenta, la estandarización de los procesos de producción agro-alimentaria y de las pautas de consumo masivo han fomentado una mundialización, con su consiguiente "deslocalización", de los sistemas de producción alimentaria (Goodman y Watts, 1997; Ilbery, 2001). Los protagonistas clave en este proceso mundializador han sido las grandes multinacionales del sector agroalimentario, así como distribuidores y detallistas. Todos ellos han fomentado la producción en serie de productos agro-alimentarios y funcionan en redes muy industrializadas y cada vez más mundializadas. Un ejemplo clásico de este desarrollo global es MacDonalds (Ritzer, 1996 ; Schlosser, 2001). Sin embargo, la globalización de la producción agro-alimentaria y de las redes de consumo es parcial, desigual y controvertida, (Ilbery et al.,2000). Efectivamente existen diferencias geográficas considerables en la integración de lo agrario en ese sistema agro-alimentario global y muy industrializado. De hecho la "industrialización" agrícola, basada en la "lógica productivista" (Allaire y Sylvander, 1997) tiende a concentrarse en regiones altamente productivas caracterizadas por grandes explotaciones agrarias que adoptan métodos de producción intensiva. Tales regiones, entre las que se encuentran la cuenca de París, Emilia Romagna, el sur de Holanda o East Anglia, suponen aproximadamente el $80 \%$ de la producción agrícola en la Unión Europea y tan sólo un 20\%, aproximadamente, de sus explotaciones agrarias. Por lo tanto, la mayor parte de las explotaciones agrarias europeas ha quedado al margen del sistema agro-alimentario global y se emplazan en regiones rurales "retrasadas". Junto con la patente desigualdad espacial, cada vez es más evidente que la industrialización agraria es inestable. Pruebas claras de todo ello son el deterioro medioambiental (por la erosión del suelo, la eliminación de lindes o la contaminación del agua), el endeudamiento de las explotaciones, la superproducción de muchos productos agrarios y la inquietud de la opinión pública en relación con la salubridad de los alimentos, motivado esto último por la proliferación de organismos genéticamente modificados, así como por diversas crisis que se han sucedido en los últimos años: encefalopatía espongiforme bovina, la enfermedad de E.Coli, la epidemia de fiebre aftosa, etc.

Pese a tales tendencias hacia la globalización alimentaria, también está claro que parte de la producción ha permanecido vinculada a su espacio y en cierta medida bajo control (Murdoch y Miele, 1999). En efecto, un sistema agro-alimentario local alternativo, basado en prácticas de consumo y de producción no estandarizadas, así como en una "lógica de calidad" (Allaire y Sylvander, 1977), está ahora recuperando su antigua importancia, brindando nuevas oportunidades a productores que venían manteniendo métodos de producción agro-alimentaria tradicionales, así como a quienes se suman a dichos métodos. (Hinrichs, 2000; Murdoch et al., 2000). Por ello, junto a los procesos de deslocalización ya citados hay todo un movimiento de relocalización de la producción y el consumo alimentarios. Este es un movimiento de índole 
cultural principalmente, influenciado por una serie de factores interrelacionados (Ilbery y Kneafsey, 2000a) como son:

a) Los atributos de estilo de vida, dado que el consumo de determinadas clases de alimentos se ha convertido en una declaración de gusto, moda, sofisticación y posición social por parte de "gourmets" relativamente acomodados.

b) El interés por la alimentación saludable, suscitado por una concienciación pública creciente respecto de las implicaciones éticas y medioambientales de la "explotación productivista", así como por la moda de la comida sana, la apariencia y el estar en forma en general, de lo que deriva también un interés por un mejor conocimiento de los alimentos.

c) La valoración de la naturaleza, la cultura y el patrimonio culinario, ya que los productos agro-alimentarios de ámbito local se han convertido en expresión de identidad cultural en una sociedad que se nutre cada vez más de signos, símbolos, sueños e imaginaciones (Nygård y Storstad, 1998; Hopkins, 1998). Existe un interés nostálgico por lo rural como un lugar de ocio, artesanía, comida tradicional y productos de "calidad".

d) El desarrollo rural endógeno, dado que los productos alimentarios y bebidas se promocionan como un instrumento de desarrollo rural, en particular en las regiones que han quedado al margen de la globalización del sistema agro-alimentario.

Por consiguiente, la relocalización de los sistemas de producción agro-alimentaria está relacionada con las cada vez más numerosas demandas de alimentos cuyo origen geográfico sea genuino y reconocible. Lo cual representa una oportunidad para que las regiones marginales agrarias no sólo desarrollen sistemas de producción agroalimentaria más sostenibles, sino también atiendan a nichos de mercado específicos o a subgrupos de consumidores con gustos, estilos de vida y aspiraciones particulares. Por eso, este artículo analiza los intentos de fomentar la relocalización de los sistemas de producción agro-alimentaria, primero en el ámbito de la UE y luego con referencia concreta al Reino Unido. Sin embargo, antes de examinar las muestras de los casos analizados, es necesario definir el marco teórico mediante el análisis de algunos conceptos relativos a los vínculos entre producto y lugar.

\section{La vinculación del producto a un lugar}

La vinculación previa entre los alimentos y determinados lugares es un requisito necesario para relocalizar los sistemas de producción agro-alimentaria. Al asociar los productos con indicadores culturales o imágenes locales, como paisajes, tradiciones, 
monumentos, se incrementa su valor porque los consumidores identifican determinados productos con lugares específicos. Dicha "fijación" del producto al lugar viene reforzada por acciones de marketing y promoción, en las que se crean imágenes distintivas de un lugar, con lo que dicho producto se vende asociándolo a ese lugar. Ray (1998) describe este proceso como "la revalorización del lugar a través de la identidad cultural". A continuación, se señalan tres conceptos que tienen una relevancia directa para la comprensión de tales vínculos entre producto y lugar.

\subsection{La calidad}

Cuando se asocia un producto a un territorio, hay una asunción de que la calidad de los productos agroalimentarios locales ( $P A L$ en lo sucesivo) es directamente atribuible a la localización geográfica de la producción, lo que constituye asimismo su garantía. Por eso se considera que los alimentos de clara procedencia local son de mayor calidad, sobre todo si satisfacen una "nostalgia" ${ }^{2}$ actual que nos remonta a tiempos en los que los productos parecían "auténticos" y "Saludables" (Gilg y Battershill, 1.998). Pero la calidad es una construcción social, cuyo significado varía según los $P A L$, los individuos, las regiones y los países. Además, la calidad se define haciendo referencia a otros conceptos socialmente constituidos como "auténtico", "beneficioso para la salud" y "tradicional. Por lo tanto, está bastante claro que la calidad puede medirse de distintas maneras (Ilbery y Kneafsey, 2000b; Murdoch et al., 2000). Por ejemplo, y como ya se ha indicado, la calidad puede transmitirse a través de la asociación de un producto con un lugar, ambiente, cultura o tradición determinados. Otro indicador de la calidad son las especificaciones (o pliego de condiciones) relativas a las materias primas, los métodos de producción y - en su caso- a la elaboración; es bastante probable que los productores de PAL hagan hincapié en este aspecto por encima de otros indicadores de calidad. Asimismo, la calidad puede ser objeto de acreditación por agencias reguladoras, mediante una etiqueta o marca de calidad o algún otro tipo de certificación. Por último los consumidores pueden interpretar la calidad en términos de atractivo de un producto, en relación con aspectos como el gusto, la textura y la apariencia. Ciertamente todos estos "indicadores" de calidad están interrelacionados y por eso cualquier plan diseñado para favorecer el desarrollo de los $P A L$ debe tenerlos a todos en cuenta.

\subsection{El arraigo social}

Es algo generalmente aceptado que los sistemas agrarios locales están "enraizados en lugares determinados, y que sus objetivos son el ser económicamente viables para los productores y consumidores, utilizar prácticas de consumo y producción ecológicamente óptimas, y aumentar la igualdad social y la democracia entre todos los 
miembros de la comunidad" (Hinrichs, 2000, p.297). Por tanto en el ámbito de los PAL el comportamiento económico está fuertemente mediatizado por una red compleja y extensa de relaciones sociales, en la que - a su vez- el productor se inserta. Lo económico y lo social no deberían separarse dado que esto último - constituído por rasgos como el conocimiento personal y las relaciones de confianza-, resulta vital para el éxito. No obstante, frente a ese arraigo - y "re-arraigon- social de los sistemas productivos locales, Murdoch y sus colaboradores (2000) advierten del riesgo de que pueda así restringirse el "alcance del mercado" de los productos locales. Es esta una sugerencia de que, aunque los $P A L$ comienzan su desarrollo profundamente enraizados en lo local, con el tiempo deberán buscar distribuidores más lejanos y desarraigarse progresivamente.

\subsection{Las cadenas agro-alimentarias}

Estarían constituidas por "nudos de producción, distribución y consumo significativos, así como por sus respectivas conexiones, además de por las condiciones naturales, culturales y sociales que afecten al movimiento de los productos" (Hartwick, 1998, p.452). Al conectar las prácticas de consumo y producción, tanto en el ámbito espacial como social, las cadenas -o redes- de producción agroalimentaria son de importancia directa para los $P A L$ porque permiten un análisis de los nudos (por ejemplo los de producción y consumo), así como de las relaciones entre ellos. Aunque la globalización de los sistemas agro-alimentarios ha sido testigo del alargamiento y complejidad crecientes de las cadenas de producción agro-alimentaria (Barret et al., 1999), una relocalización de la producción (y el consumo) acortaría la cadena - red-y permitiría centrarse más en determinados lugares, que actúan como nudos de conexión para los movimientos de productos. Autores como Fine $(1994,1995)$ han solicitado más estudios sobre las cadenas - redes- de producción en el caso de productos o grupos de productos determinados, ya que cada uno representa un "sistema de provisión" único que puede "delinearse distintamente según la fuerza de las relaciones entre sus actividades constitutivas, en especial de las ajenas al propio consumo final" (Fine et al., 1996 p.201).

En definitiva esta breve revisión de conceptos muestra la importancia de algunas características cuando se fomenta la relocalización de los sistemas de producción agro-alimentaria. Sería pués necesario:

- Tener una idea clara de lo que se entiende por calidad y de cómo debe (o no) asociarse a lugares determinados.

- Resaltar que el comportamiento económico está fuertemente embebido de relaciones locales, condiciones sociales y de conocimiento personal. 
- Prestar mayor atención a los nudos de producción y distribución de cadenas redes- de producción agro-alimentarias determinadas, así como a las condiciones naturales, sociales y culturales propias de sus respectivas conexiones.

\section{La vinculación del producto al territorio en la Unión Europea: La «Denominación de origen protegida» y la «Indicación Geográfica Protegida»}

En 1992, la Unión Europea presentó el Reglamento 2081/92 para "proteger" y "promocionar" los $P A L$ con un origen geográfico reconocible. En virtud de este Reglamento, productores y transformadores de productos agro-alimentarios de calidad, que trabajen principalmente en grupos (si bien una persona sola también es elegible), pueden solicitar una de las siguientes calificaciones o marchamos:

- Denominación de origen protegida (DOP), destinada a los alimentos que se obtengan, transformen y elaboren utilizando métodos únicos en una zona geográfica determinada; y cuya calidad y características se deban exclusivamente a su localización en dicha área.

- Indicación Geográfica Protegida (IGP), destinada a los alimentos que se produzcan, transformen o elaboren en una determinada zona geográfica, y que cuentan con una reputación, rasgos o ciertas cualidades atribuibles a su localización en dicha zona.

La distinción clave entre la DOP y la IGP es que para DOP la vinculación geográfica debe darse en todas las fases de producción, transformación y elaboración, mientras que para la IGP debe darse al menos en una de ellas. En ambas está implícita la premisa de que la calidad del producto se intensifica mediante su asociación a un lugar o región determinados. En virtud del citado Reglamento, un producto alimentario registrado a escala europea goza de protección frente a posibles imitaciones en toda Europa. La DOP y la IGP son similares a las "Denominaciones de origen" y las "Denominaciones específicas" españolas. Así el jamón de Teruel y el queso de Cabrales son DOP, mientras que el ternasco de Aragón y la sobrasada mallorquina son IGP.

Las DOP e IGP incluyen una amplia gama de $P A L$ que van desde el agua mineral natural, la cerveza y la sidra, a la carne, productos lácteos y pescado, pasando por las galletas, pan, pasteles, productos de repostería y confitería. Sin embargo, se dan una serie de condiciones adicionales y, entre otras cosas, los productores deben utilizar nombres que contengan un elemento geográfico descriptivo que los vincule a un lugar determinado, especificar métodos de producción, y aportar pruebas históricas que vinculen el producto a ese lugar determinado. Se les pide además que dicho 
producto haya sido inspeccionado para garantizar que cumple con las exigencias de la reglamentación registrada. Por lo tanto, la concesión tanto de una certificación de DOP o de IGP depende de la utilización de materias primas y de métodos de producción determinados (especificaciones) de una zona geográfica determinada (asociación).

A finales de 1999 había 535 productos beneficiarios de DOP o de IGP en 14 países de la UE. Más del 60\% de dichos productos (332) eran de DOP. La tabla 1 ofrece un desglose de las zonas con DOP o con IGP por países. Pronto queda claro que sólo 7 países poseen el $95 \%$ de todas las denominaciones. Los 2 países más importantes son Francia con 111 registros, lo que supone el 21\% del total de los registros, e Italia que con 99 registros representa el 19\%. Aunque las DOP son más numerosas en Italia, las IGP son ligeramente más importantes en Francia. Grecia y Portugal y en menor medida España tienen también unas cifras importantes de DOP/IGP, mientras que Alemania y el Reino Unido son los dos únicos países "septentrionales" que figuran en la lista de los 7 primeros (Ilbery et al., 2000c). En efecto, hay una fuerte concentración "meridional" de DOP e IGP, mientras que los países escandinavos y del Benelux tienen tan sólo 5 y 11 denominaciones respectivamente. En lo que respecta a sectores de productos, en las DOP predominan los quesos (40\% de todas las DOP) aceites y grasas (14\%), las frutas, cereales y verduras (13\%) y las cervezas alemanas (9\%). Las carnes frescas y embuchados encabezan la lista de los productos IGP (un 32\% del total de IGP) seguidas por las frutas, los cereales y las verduras (26\%) y los productos derivados de la carne (14\%).

Tabla 1. Declaraciones de "Denominación de Origen Protegida» (DOP) y de «Indicación Geográfica Protegida» (IGP) en la Unión Europea, 1999

\begin{tabular}{|lccc|}
\hline País & DOP & IGP & Total \\
\hline Francia & 53 & 58 & 111 \\
Italia & 69 & 30 & 99 \\
Portugal & 53 & 29 & 82 \\
Grecia & 60 & 21 & 81 \\
Alemania & 37 & 25 & 62 \\
España & 27 & 17 & 44 \\
Reino Unido & 14 & 14 & 28 \\
Austria & 9 & 3 & 12 \\
Luxemburgo & 2 & 2 & 4 \\
Países Bajos & 4 & 0 & 4 \\
Bélgica & 2 & 1 & 3 \\
Dinamarca & 0 & 3 & 3 \\
Finlandia & 1 & 0 & 1 \\
Suecia & 1 & 0 & 1 \\
Irlanda & 0 & 0 & 0 \\
Total & 332 & 203 & 535 \\
\hline
\end{tabular}

Fuente: libery y Kneafsey, 2000a 
Si nos centramos más particularmente en España, las 44 denominaciones se dividen en 27 zonas con DOP y 17 con IGP. La tabla 2 ofrece esta información según los sectores de los productos. Aunque los quesos predominan en la lista de la DOP, (44\% del total de DOP), otros productos con DOP son las frutas, las verduras y los cereales, los productos derivados de la carne y el aceite de oliva. Las carnes frescas y la charcutería (35\%), así como las frutas, las verduras y los cereales (41\%), constituyen los sectores de productos más importantes en lo que respecta a IGP. En comparación con Portugal, donde las denominaciones DOP e IGP se encuentran parcialmente restringidas al sur, las DOP e IGP españolas están bastante diseminadas por todo el país (Ilbery et al., 2000). Sólo 2 de las 44 denominaciones españolas se encuentran en zonas montañosas y poco favorecidas.

La distribución geográfica de productos, los registrados bajo DOP o IGP en la Unión Europea refleja la especialización agraria de cada país. Por ejemplo: los quesos en Francia, los quesos y carnes transformadas en Italia y las cervezas en Alemania. También reflejan las tradiciones culturales y gastronómicas de alimentos "típicos" o locales de muchos países del sur de Europa frente a los "alimentos de ninguna parte" del norte de Europa (Ilbery y Kneafsey, 2000a). Por lo tanto cabe concluir (Ilbery et al, 2000) que la adopción de DOP o de IGP será mayor cuando coincidan dos factores: la importancia cultural e histórica de los productos alimentarios locales, primero, y también la existencia de cooperativas de productores. Ninguno de estos dos factores, por ejemplo, es particularmente importante en el Reino Unido y por eso algunos productores que tienen IGP han formado "grupos de conveniencia” para obtener la denominación, pero siguen trabajando de modo independiente (Ilbery y Kneafsey, 2000a).

Tabla 2. Declaraciones de «Denominación de Origen Protegida» (DOP) y de «Indicación Geográfica Protegida» (IGP) en España, 1999

\begin{tabular}{|lccc|}
\hline Tipos de productos & DOP & IGP & Total \\
\hline Frutas, verdures y cereales & 6 & 7 & 13 \\
Queso & 12 & 0 & 12 \\
Carne fresca/embuchados & 0 & 6 & 6 \\
Productos cárnicos & 4 & 2 & 6 \\
Aceite de oliva & 4 & 0 & 4 \\
Productos de panadería, & & & \\
Pastelerla y confitería & 0 & 2 & 2 \\
Miel & 1 & 0 & 1 \\
Total & 27 & 17 & 44 \\
\hline
\end{tabular}

Fuente: Ilbery et al, 2000 


\section{Características de las producciones certificadas (DOP e IGP) en Gran Bretaña}

Un estudio sobre productores beneficiarios de DOP o de IGP en Gran Bretaña (Ilbery y Kneafsey, 2000a), ha resaltado la importancia de una serie de aspectos relativos a la organización de la empresa, la calidad, las cadenas de producción agro-alimentaria y su inserción social. En primer lugar, sólo tres de las empresas con DOP o IGP pueden describirse como pequeñas y medianas empresas; de hecho algunas de ellas formaban parte de enormes empresas como Scottish and Newcastle plc y Dairy Crest. En segundo lugar, "la diferenciación del producto", "la asociación a una región" y "la percepción del consumidor" surgieron como los tres indicadores más importantes de calidad. Las primas a los precios y métodos de producción tenían también gran importancia. En tercer lugar, muy pocos de los productores implicados se caracterizan por vender sus productos directamente al consumidor final. En lugar de eso, las cadenas de producción agro-alimentaria son más largas y se extienden más allá del ámbito local. Los supermercados representan el $40 \%$ o más de las ventas en cuatro de los casos, porcentaje que es ampliamente mejorado en otras seis empresas donde los mayoristas realizan entre un 50 y un $90 \%$ de las ventas. Por eso a los productores en zonas con DOP o IGP no les preocupa realmente el consumidor final en la última fase de la cadena alimentaria. Esto da lugar a un cuarto aspecto fundamental de las empresas británicas con designación de DOP o de IGP: que tienen un nivel bajo de arraigo social y que se mueven por fuertes imperativos económicos, donde las consideraciones de competencia y precio son características clave. Por eso las empresas beneficiarias de DOP o de IGP en el Reino Unido tienen un largo camino por delante para desarrollar vínculos sólidos entre producto y lugar, si se considera que los productos alimentarios locales son una parte integral y simbólica de identidades regionales, como lo son en muchas regiones del sur de Europa.

\section{Vinculación de producto a lugar en el Reino Unido: agrupaciones de alimentos regionales}

Hoy en día se reconoce que los $P A L$ constituyen un importante nicho de mercado en el Reino Unido y el organismo Food From Britain ("Alimentos de Gran Bretaña") se encarga del desarrollo de especialidades productivas regionales (Summerfield, 2000). Con el apoyo financiero del Ministerio de Agricultura, Pesca y Alimentación el citado organismo ha ayudado al establecimiento en Inglaterra de seis agrupaciones regionales de alimentos y bebidas, a las que se añade algún otro grupo de carácter más local (figura 1). El objetivo es fomentar el crecimiento de las pequeñas y medianas empresas en el sector de los $P A L$, y apoyar a los productores, a los que se des- 


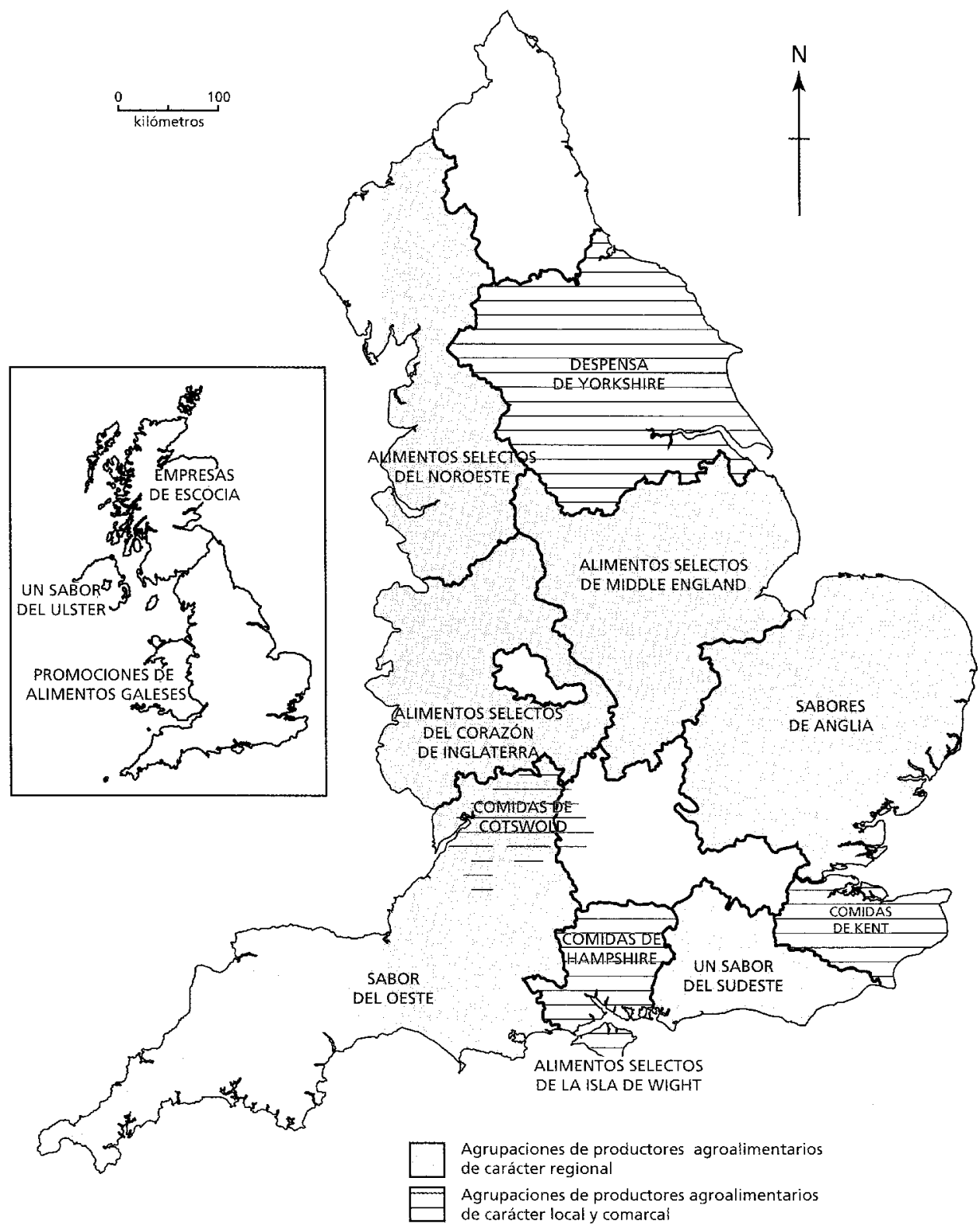

Figura 1 
cribe de la siguiente manera: "pequeñas empresas dedicadas a la elaboración de productos de alta calidad. Tanto si están trabajando con una fórmula tradicional como si lo hacen con un producto innovador, comparten el compromiso de mantener las cualidades asociadas a los productos artesanos confeccionados con mimo y cuidadon.

Como han señalado Ilbery y Kneafsey (2000b), "Alimentos de Gran Bretaña" tiene como objetivos:

- Actuar como un "consejero matrimonial" entre los productores de PAL y los minoristas, grupos proveedores de comidas preparadas así como otros importantes distribuidores.

- Garantizar a los productores de PAL una resonancia adecuada en Ferias nacionales e internacionales.

- Desarrollar mercados de exportación para los PAL de Gran Bretaña.

- Gestionar actividades de relaciones públicas y crear una identidad para los AL británicos.

- Cuando sea necesario, ser el adalid del desarrollo de empresas independientes.

Por su parte las seis agrupaciones de alimentos regionales se comprometen a fomentar un enfoque "ascendente" (botton-up) del desarrollo rural y además a ser capaces de:

- Ofrecer una amplia gama de productos que atraiga a los compradores.

- Conseguir acceder a los mercados.

- Obtener financiaciones de la UE u otras.

- Organizar certámenes y ferias comerciales.

- Proporcionar formación en diversas materias, como por ejemplo marketing y seguridad alimentaria.

Taste of the West (TOW, "Sabor del Oeste") fue el primer grupo regional que se constituyó. Con base en los condados de Cornwall, Devon, Dorset, Sommerset, Gloucestershire y Whiltshire en el suroeste de Inglaterra, TOW cuenta con más de 190 productores miembros, los cuales están inmersos en la producción de una variada gama de productos. La adhesión a la agrupación depende de una serie de criterios, para así garantizar que "el producto es único, regional, tradicional o artesano, o que se destina a un nicho de mercado". El análisis realizado por Ilbery y Kneafsey (2000b) 
y Kneafsey e Ilbery (2001) a una muestra de 55 miembros de TOW (de los 100 a los que se envió un cuestionario), revela descubrimientos interesantes con relación a la calidad, cadenas de producción y arraigo local, asi como contrastes significativos en relación con los productores británicos acogidos a las medidas comunitarias de certificación, DOP e IGP.

En primer lugar, a diferencia de las relativamente grandes empresas que se asocian a las DOP y a las IGP, la mayor parte de estas empresas, el 90\%, son aquí familiares y una de cada cuatro tienen su sede en pequeñas explotaciones. En segundo lugar, las especificaciones (o pliego de condiciones) surgen como un indicador clave de calidad, mientras que la atracción, la asociación y la certificación son mucho menos importantes. Por eso, los productores hacen hincapié en la importancia de los "ingredientes", "la calidad de las materias primas", "la coherencia del proceso de producción", "las recetas", "la atención al detalle" y "el saber hacer". En comparación con los productores de áreas con DOP o IGP, los miembros de TOW clasifican "la textura, el sabor y el gusto", "las materias primas" y "los métodos de producción" como los tres “indicadores" más importantes de calidad.

En tercer lugar los productores de TOW, como sus homólogos con DOP o IGP, suelen desconocer dónde se venden sus productos una vez que pasan a manos de sus distribuidores y del resto de la cadena alimentaria. No obstante, aunque los productores acogidos a las DOP/IGP tienden a favorecer a los mayoristas y distribuidores de supermercados, los productores TOW se apoyan más en compradores y minoristas locales; en efecto, gran parte confía en la construcción de "relaciones de confianza" y "contacto personal" con "agentes" del sistema regional de producción agro-alimentaria. Sólo una minoría de los productores de la agrupación trata con supermercados de modo regular.

En cuarto y último lugar, resulta bastante común entre los miemros de TOW el uso de "imaginería. diversa en las etiquetas y envases para anunciar y promocionar los alimentos locales, pero es significativo que apenas desarrollen el vínculo entre la calidad y la región o lugar específico. (Kneafsey e Ilbery, 2001).

Aunque los principios económicos son importantes para los productores de $70 \mathrm{~W}$, los aspectos del precio y la competencia no son lo único que se tiene en cuenta. Un número considerable de productores (un 57\% aproximadamente) se había trasladado al suroeste de Inglaterra bien para establecer su negocio, bien para mejorar la calidad de su estilo de vida, o ambos fines a la vez. Por eso las consideraciones no económicas y el comportamiento social son características de la mayor importancia, como lo es también una creencia en sistemas agrarios naturales, sostenibles y locales más firme que la de los productores en áreas de DOP o de IGP. Resulta claro también que los empresarios de TOW están bastante más integrados socialmente que sus colegas beneficiarios de DOP o IGP. Sin embargo, incluso aquí el grado de integración en las relaciones sociales locales es limitado porque, como ya se ha dicho, los productores mues- 
tran relativamente poca preocupación por el consumidor final y no suelen promocionar explícitamente el vínculo entre su producto y el lugar. En otras palabras, y a diferencia de lo que ocurre a menudo en Francia y en otras regiones del sur de Europa, no existe entre los productores de TOW, como tampoco entre los otros británicos adscritos a las DOP o a las IGP, un sentido general de identidad territorial coherente.

\section{Conclusión}

En este artículo se ha mantenido que los productos alimentarios locales, de origen geográfico reconocible y autentificable, pueden constituir una oferta viable y alternativa a las operaciones globales de los gigantes de la alimentación, detallistas y supermercados. Esta relocalización de la producción es particularmente adecuada para aquellas regiones rurales socioeconómicamente menos avanzadas y excluídas del grupo de las más altamente productivas en términos agrícolas de la Unión Europea. La relocalización puede interpretarse como una respuesta a una serie de factores de "repulsión" y "atracción" 3 (push" y "pull"). Los primeros se refieren a las desventajas de los sistemas agrarios productivistas, dramáticamente ilustradas por la pasada crisis de la fiebre aftosa que a mediados de 1991 había afectado ya a más de 1.400 explotaciones en el Reino Unido. Entre los segundos se incluye la importancia cultural creciente de la alimentación y de la comida sana, así como los estilos de vida característicos del "nuevo consumidor".

Sin embargo, dicho proceso de relocalización supone la "fijación" consciente de un producto a un lugar, lo que resulta más difícil en el norte de Europa, y en el Reino Unido en particular, que en los países del sur de Europa donde ya existe una fuerte cultura de alimentos regionales. En este sentido hay que señalar tres aspectos relevantes:

- Primero, que la calidad es una construcción social y que el concepto "alimentos de calidad" tiene diferentes significados para los diferentes "agentes" involucrados en el sistema de producción agro-alimentario;

- Segundo, que es necesario que los productores de PAL se "extiendan" más allá del ámbito local y buscar mercados más distantes.

- Tercero, que existe el peligro de que grandes distribuidores y supermercados se apropien de la calidad de los $P A L$, y de hecho ya muchos anuncian, mediante planes de garantía de calidad (Morris y Young, 2000), que suministran productos agro-alimentarios "Sanos", "artesanos" $y$ "frescos".

Las evidencias encontradas en investigaciones sobre el Reino Unido (Ilbery y Kneafsey, 2000a y b) sugieren, por lo que a los productos de áreas con DOP e IGP 
respecta, un sesgo hacia empresas más grandes que no se preocupan realmente por el consumidor final, en la última fase de la cadena agro-alimentaria. Estas empresas no han desarrollado vínculos particularmente fuertes entre producto y lugar, tienen niveles relativamente bajos de arraigo social y, por lo tanto, no forman parte integral de las identidades regionales respectivas. Contrastando con esta situación, los miembros del grupo regional alimentario TOW se apoyan en mayor medida en distribuidores y minoristas locales, haciendo un gran hincapié en las "relaciones de confianza" y los "contactos personales". Existe un vínculo más fuerte entre producto y lugar y, por ello, niveles más altos de arraigo social dentro del área local. No obstante, la mayoría de los productores sigue mostrando también poco interés por el consumidor final, y rara vez desarrollan el vinculo entre calidad y un lugar determinado en el etiquetado de su producto y en iniciativas de marketing. Por lo tanto, se aprecia en general poca conciencia de una identidad territorial coherente entre este grupo de productores.

Estas conclusiones plantean varios retos con vistas a proseguir la relocalización del sistema de producción agro-alimentaria, en particular en el norte de la UE. Dichos retos conciernen a diferentes agentes del sistema de producción agro-alimentaria. En primer lugar, los reguladores institucionales necesitan desarrollar estrategias para los PAL que tengan más en cuenta lo espacial, así como construir una identidad territorial más sólida y coherente; incluso si este objetivo se consiguiera, deberá dedicarse mayor atención a proteger dicha identidad. En los planes de las DOP e IGP dicho objetivo se ha perseguido mediante la protección de los $P A L$ con origen geográfico, pero el presente artículo muestra un claro sesgo de las concesiones hacia las regiones meridionales europeas.

En segundo lugar, los productores de $P A L$ necesitan desarrollar mercados, tanto distantes como locales, para sus productos si quieren garantizarse un desarrollo sostenible. Ello supone establecer simultáneamente sólidas redes "verticales" de consumidores de fuera de su ámbito local (por ejemplo a través de minoristas y de internet), así como redes "horizontales" de consumidores en el ámbito local inmediato (por ejemplo, a través del marketing directo y de distribuidores minoristas locales). Sin embargo existe el riesgo de que el incremento de la escala de producción tenga consecuencias adversas para la calidad, el arraigo, las alianzas con los clientes y las relaciones de confianza. En todo caso los productores de $P A L$ parecen hacer más hincapié en la calidad del producto, a través de las especificaciones, a expensas de comercializar la identidad territorial.

En tercer lugar, los consumidores necesitan ser más conscientes del "lo territorial" como distintivo de los alimentos de alto valor y calidad. Existe sin duda un incremento de la demanda de $P A L$, pero el conocimiento del consumidor sobre denominaciones de origen e indicaciones geográficas protegidas, sobre los origenes geográficos de los productos, y sobre las distintas ofertas alimentarias locales - como agrupaciones de productores, cooperativas de comercialización, productos de agricultura ecológica, etc.-, es bastante limitado en la actualidad. Por último, todo el tema de la relocali- 
zación de los sistemas de producción agro-alimentaria requiere un análisis más exhaustivo, mediante métodos cualitativos que "desenmarañen" las complejidades de conceptos tales como calidad, "enraizamiento productivo" y "cadenas de produción".

\section{Notas}

1 Traducción de María Gálvez

2 En español en el original (N.T)

3 "Push" y "pull" en el original (N.T.)

\section{Bibliografía}

Allaire, G. Y.; Sylvander, B. (1997): Qualité spécifique et système d'innovation Territoriale. Cabiers d'économie et sociologie rurales 4, p. 30-59.

Barrett, H.; Ilbery, B.; Browne, A. y Binns, T. (1999): Globalization and the changing networks of food supply: the importation of fresh horticultural produce from Kenya into the UK Transactions of the Institute of British Geographers, 24, p. 159-74.

Bell, D. y Valentine, G. (1997): Consuming geographies: we are where we eat. Londres, Routledge.

Fine, B. (1994): Towards a political economy of food. Review of International Political Economy, 1, p. 519-45.

Fine, B. (1995): From political economy to consumption. En Miller, D. (ed) Acknowledging consumption. Londres, Routledge.

Fine, B.; Heasman, M. y Wright, J. (1995): Consumption in the age of affluence: the world of food. Londres, Routledge.

Gilg, A. y Battershill, M. (1998): Quality farm food in Europe: A possible alternative to the industrialised food market and to current agri-environmental policies: lessons from France. Food Policy, 23, p. 25-40.
Goodman, D. y Watts, M., ed. (1997): Globalising food: agrarian questions and global restmicturing. Londres, Routledge.

Hartwick, E. (1998): Geographies of consumption: a commodity chain approach. Environment and Planning D: Society and Space, 16, p. 423-37.

Hinrichs, C. (2000): Embeddedness and local food systems: notes on two types of direct agricultural market. Journal of Rural Studies, 16, p. 295-303.

Hopkins, J. (1998): Signs of the post-rural: marketing myths of a symbolic Countryside. Geografiska Annaler, 80B, p. 65-81.

Ilbery, B. (2001): Changing geographies of global food production. En Daniels, P.W., Bradshaw, M.; Shaw, D. y Sidaway, J. (eds) Human geography: issues for the $21^{\text {st }}$ century. Londres, Prentice Hall, pp. 253-73.

Ilbery, B. y Kneafsey, M. (2000a): Registering regional speciality food and drink products in the UK: the case of PDOs and PGIs. Area, 32, p. 317-326.

Ilbery, B. y Kneafsey, M. (2000b): Producer constructions of quality in regional speciality food production: a case study from 
south west England. Journal of Rural Studies, 16, p. 217-30.

Ilbery, B.; Kneafsey, M. y Bamford, M. (2000): Protecting and promoting regional speciality food and drink products in the European Union. Outlook on Agriculture, 29, p. 31-37.

Kneafsey, M. e Ilbery, B. (2001): Regional images and the promotion of speciality food and drink products: initial explorations from the 'West Country'. Geograpby, 86, p. $131-40$

Morris, C. y Young, C. (2000): Seed to shelf, 'teat to table', 'barley to beer' and 'womb to tomb': discourses of food quality and quality assurance schemes in the UK. Journal of Rural Studies , 16, p. 103-115.

Murdoch, J. y Miele, M. (1999): Back to nature: changing worlds of production in the food sector. Sociologia Ruralis, 39, p. 465-483.
Murdoch, J., Marsden, T. y Banks J. (2000) Quality, nature and embeddedness: some theoretical considerations in the context of the food sector. Economic Geography, 76 , p. 107-25.

Nygård, B. y Storstad, O. (1998): De-globalisation of food markets? Consumer perceptions of safe food: the case of Norway. Sociologia Ruralis, 38, p. 33-53.

Ray, C. (1998): Culture, intellectual property rights and territorial rural development. Sociologia Ruralis, 38, p.1-19.

Ritzer, G. (1996): The McDonaldization of society. california, Pine Forge Press.

Schlosser, E. (2001) : Fast food nation: the dark side of the all-American meal. Nueva York, Houghton Miflin,

Summerfield, G. (2000): Speciality food and drink from Britain. Journal of the Royal Agricultural Society of England, 161, p. 49-54. 